Photo Credit: U.S. Fish and Wildlife Service, Mexican Wolf Interagency Field Team 


\section{Evaluating Trapping Techniques to Reduce Potential for Injury to Mexican Wolves}

By T.T. Turnbull, J.W. Cain, III, and G.W. Roemer

Open-File Report 2011-1190 


\section{U.S. Department of the Interior \\ KEN SALAZAR, Secretary \\ U.S. Geological Survey \\ Marcia K. McNutt, Director}

U.S. Geological Survey, Reston, Virginia: 2011

This and other USGS information products are available at http://store.usgs.gov/

U.S. Geological Survey

Box 25286, Denver Federal Center

Denver, C0 80225

To learn about the USGS and its information products visit http://www.usgs.gov/ 1-888-ASK-USGS

Any use of trade, product, or firm names is for descriptive purposes only and does not imply endorsement by the U.S. Government.

Although this report is in the public domain, permission must be secured from the individual copyright owners to reproduce any copyrighted materials contained within this report.

Suggested citation:

Turnbull, T.T., Cain, J.W., III, and Roemer, G.W., 2011, Evaluating trapping techniques to reduce potential for injury to Mexican wolves: U.S. Geological Survey Open-File Report 2011-1190, 11 p. 


\section{Acknowledgments}

Funding was provided by the New Mexico Department of Game and Fish. Reviews by M. J. Kauffman and P.R. Krausman improved an earlier draft of this report. 


\section{Contents}

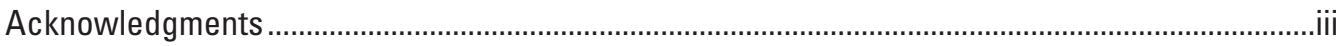

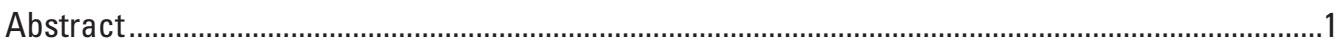

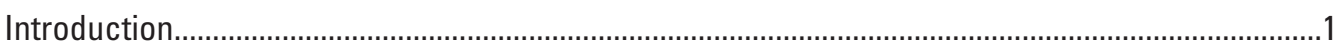

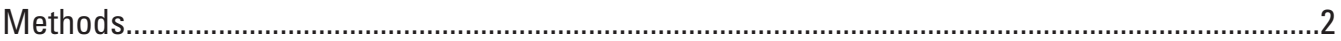

Sources of Mortality and Trapping Incidents for Mexican Wolves ..........................................2

Trap-Injured Wolves and Cattle Depredation ...........................................................................

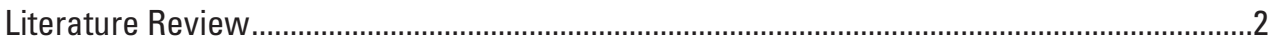

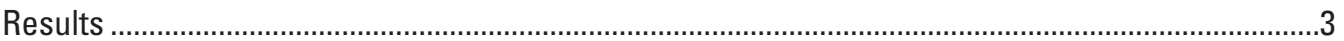

Sources of Mortality and Trapping Incidents for Mexican Wolves ...........................................

Trap-injured Wolves and Cattle Depredation...............................................................................

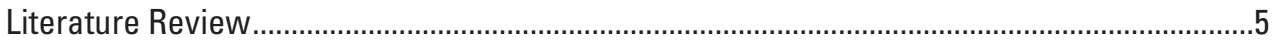

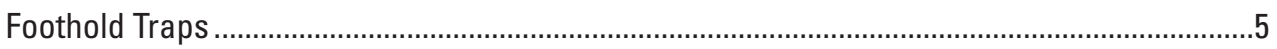

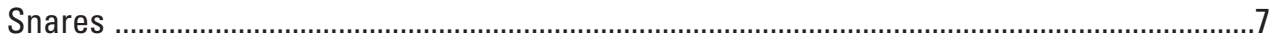

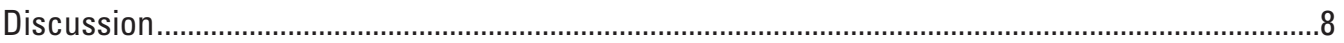

References Cited

\section{Figures}

1. Known sources of mortality for Mexican wolves (Canis lupus baileyi)

in Arizona and New Mexico, 1998-2010.

\section{Tables}

1. Known nonrecovery program-related (that is, private) trapping incidents for Mexican wolves (Canis lupus baileyi) in Arizona and New Mexico, 1998-2010

2. Mean injury score for coyotes (Canis latrans) from studies evaluating capture injuries resulting from the use of foothold traps and nonlethal cable snares

3. Percentage of wolf (Canis lupus) injuries by severity class summarized from studies evaluating wolf injuries caused by various types of foothold traps. In general, the severity of the injury increases with the severity score

4. Mean injury score for red fox (Vulpes vulpes), coyotes (Canis latrans), and wolves (Canis lupus) from studies evaluating capture injuries resulting from the use of foothold traps and nonlethal cable snares 


\title{
Evaluating Trapping Techniques to Reduce Potential for Injury to Mexican Wolves
}

\author{
By Trey T. Turnbull,, James W. Cain III, ${ }^{2}$ Gary W. Roemer ${ }^{1}$
}

\section{Abstract}

Increased scrutiny of furbearer trapping has resulted in more regulation and even prohibition of common trapping methods in some States. Concerns regarding the potential negative impacts of regulated furbearer trapping on reintroduced Mexican gray wolves (Canis lupus baileyi) led now former Governor Bill Richardson to issue an executive order prohibiting trapping in the New Mexico portion of the Blue Range Wolf Recovery Area (BRWRA). This ban was to last for at least 6 months and required an evaluation of the risk posed to wolves by traps and snares legally permitted in New Mexico. We reviewed various threats to wolves in the BRWRA, including threats posed by regulated furbearer trapping. Seventy-eight Mexican wolf mortalities were documented during the reintroduction effort (1998-2010). More than 80 percent of documented mortalities were humancaused: illegal shooting (47.4 percent), vehicle collisions (15.4 percent), lethal removal by the U.S. Fish and Wildlife Service (USFWS) (14.1 percent), nonproject-related trapping (2.6 percent), project-related trapping (1.3 percent), and legal shooting by the public ( 1.3 percent). The remaining 17.9 percent of mortalities were a result of natural causes. An additional 23 wolves were permanently removed from the wild by USFWS. Of 13 trapping incidents in New Mexico that involved trappers other than USFWS project personnel, 7 incidents resulted in injuries to wolves, 2 wolves sustained injuries severe enough to result in leg amputations, and 2 wolves died as a result of injuries sustained. Rubber-padded foothold traps and properly set snares would most likely reduce trap-related injuries to Mexican wolves; however, impacts caused by trapping are outnumbered by other, human-caused impacts.

\section{Introduction}

Trapping of furbearers for recreation or wildlife damage mitigation, while a long-standing tradition in the United States and other parts of the world, has received increased scrutiny by the public in recent years because commonly used trapping practices have been perceived as being inhumane (Onderka and others, 1990; Andelt and others, 1999). These concerns have led to increased regulation and even total prohibition of common trapping methods in some jurisdictions (Muth and others, 2006). Additionally, wildlife professionals often need to capture animals for study, and injured animals could bias results. As a result, a number of field projects have been conducted comparing various types of traps and methods in order to find solutions that minimize trauma to target and nontarget animals (Andelt and others, 1999; Frame and Meier, 2007). Similar concerns about animal welfare and public perception of trapping led to the development of the "Best Management Practices" (BMPs) for furbearer trapping in the United States by the Association of Fish and Wildlife Agencies (IAFWA, 1997). Given the potential for further restrictions being placed on trappers, such as potential bans on importation of furs collected by using certain methods (Proulx and others, 1994), testing of different devices to evaluate their impacts and identify means of mitigation for those impacts is likely to continue.

The potential impacts of regulated furbearer trapping on reintroduced Mexican wolves (Canis lupus baileyi) in New Mexico has become a concern of some sectors of the public and, in part, prompted now former New Mexico Governor Bill Richardson to issue Executive Order 2010-029 (Temporary Ban of Trapping in the Blue Range Wolf Recovery Area) on July 28, 2010. The Executive Order directed the

\footnotetext{
${ }^{1}$ Department of Fish, Wildlife, and Conservation Ecology, New Mexico State University, Las Cruces, NM 88003, USA

${ }^{2}$ U.S. Geological Survey, New Mexico Cooperative Fish and Wildlife Research Unit, Department of Fish, Wildlife, and Conservation Ecology, New Mexico State University, Las Cruces, NM 88003, USA
} 
New Mexico Department of Game and Fish (NMDGF) to prohibit trapping in the New Mexico portion of the BRWRA for at least 6 months to allow a study to be conducted that would evaluate the risk posed to wolves by different types of traps and snares legally permitted in New Mexico. All previously legal methods to capture furbearers were prohibited except for residents trapping specifically to protect domesticated animals, or trapping of species not regulated by the NMDGF (for example, coyote [Canis latrans]).

We reviewed scientific reports and other sources of information relevant to human-caused threats to wolves, including potential impacts from legally permitted traps and snares in the BRWRA to assist NMDGF in complying with EO 2010-029. Our specific objectives were to (1) review known sources of mortality and trapping incidents for Mexican wolves; (2) evaluate the potential risk of permanent injury or death to Mexican wolves resulting from the use of each trap or snare type currently allowed in New Mexico; and (3) identify trap and snare types, associated techniques, and potential modifications that may reduce risk of permanent injury or death to Mexican wolves by regulated furbearer trapping. Our review was primarily limited to trap types and snares legally permitted in New Mexico; more comprehensive reviews are found elsewhere (Iossa and others, 2007).

\section{Methods}

\section{Sources of Mortality and Trapping Incidents for Mexican Wolves}

We obtained information on sources of mortality and trapping incidents for Mexican wolves by request from the USFWS and by reviewing annual reports (USFWS, 2011a) and monthly updates on the Mexican Wolf Recovery Program (USFWS, 2011b). We reviewed information to determine the number of nonproject-trapping incidents (that is, unrelated to USFWS Mexican Wolf Recovery Program) involving Mexican wolves, injury status of trapped wolves, and current fate of wolves involved in these incidents. We attempted to obtain information on the trap types (and any modifications thereof) and anchoring mechanisms used, as well as species being targeted by nonproject trappers. We also requested information on the known causes of mortality for all wolves during the recovery program.

\section{Trap-Injured Wolves and Cattle Depredation}

To determine if depredation of livestock increased following trap-related injuries, we reviewed information to determine the number of depredation incidents in which wolves were involved both prior to and after they were injured in nonproject trapping incidents. Based on the available information, we were unable to determine if multiple livestock injuries inflicted by wolves on the same day were distinct or if more than one cow was injured in the same incident; therefore, we treated each livestock injury as a separate incident.

\section{Literature Review}

We used Google Scholar, Journal Storage (JSTOR), and Web of Science to search the scientific literature (both peer-reviewed literature and unpublished reports) for studies that compared trap-related injuries and examined trap-injury mitigation. We used the following search terms: trap injury, foothold trap injury, leghold trap injury, foothold trap trauma, leghold trap trauma, wolf trap injury, furbearer trap injury, coyote trap injury, and bobcat (Lynx rufus) trap injury. We entered search terms without quotations, so exact word order was not required of search results, and searches were the broadest offered by each site (that is, not narrowed down by searching only keywords or only abstracts). Articles were deemed appropriate for review if they focused on trap-injury mitigation and/or best practices associated with trapping wolflike canids (for example, members of the genus Canis) or trap sizes were consistent with those used on canids (for example, bobcat studies). We further restricted the results of initial literature searches to only those trap types allowed by law in New Mexico and to regulated furbearer species and coyote because the size of traps commonly used by trappers targeting these species may present a risk of injury for Mexican wolves (NMDGF, 2011). We did not include lethal, Conibear-style traps in this review. In addition to content review, we reviewed the literature cited sections to find other relevant literature. We used tools available through Google Scholar, JSTOR, and Web of Science to locate articles citing those we had already obtained. This process was repeated on each new source, eventually reaching a point when no new, relevant material was discovered.

We also requested information on the average injury scores and sample sizes for each trap type recommended for use in the "Best Management Practices for Trapping in the United States" for wolves, coyote, and bobcat published by the Association of Fish and Wildlife Agencies (AFWA, 2003, 2006a,b,c). The BMPs resulted from extensive studies, with relatively large sample sizes, evaluating animal welfare, efficiency, selectivity, practicality, and safety of a large number of trap types. Trauma scales used in the BMPs followed guidelines presented in the International Organization for Standardization (ISO, 1999). Trap types with an average cumulative injury score of greater than or equal to 55 on one scale, or greater than or equal to 70 percent of a sample with "no injuries or mild-moderate trauma" met the BMP animal welfare criteria (AFWA, 2006a). Because of the scope of this report, we requested data pertaining only to animal welfare. 


\section{Results}

\section{Sources of Mortality and Trapping Incidents for Mexican Wolves}

Between 1998 and 2010, the USFWS documented 78 mortalities of Mexican wolves (USFWS, 2010). Thirty-seven wolves were illegally shot, 12 were hit by vehicles, 11 were lethally removed by the USFWS, 2 died from trap-related injuries resulting from traps set by nonproject trappers, 1 was legally shot by the public, 1 died from trap-related injury during the course of USFWS research operations, and 14 died of natural causes (fig. 1). During this same period, 23 wolves were permanently removed from the wild by the USFWS. Thus, over a 12-year period, 101 wolves in total were removed from the wild; only 50 wolves were estimated to be alive in the wild in 2010 (J. Oakleaf, USFWS, written commun.).
Fourteen individual wolves were captured in foothold traps set by trappers other than USFWS project personnel 15 times during the course of the reintroduction effort (table 1); female wolf 562 was captured twice. Thirteen of these incidents occurred in New Mexico, and 7 wolves incurred injuries as a result; 5 were apparently uninjured; and the injury status is unknown but suspected for 1 (table 1). Two wolves died as a result of injuries sustained, 2 sustained injuries severe enough to result in leg amputations, and 1 wolf had toes amputated and the pad removed from the right foot (table 1). The 2 wolves that had legs amputated were either alive as of April 2011 (M871) or were alive until January 2009 but current fate is unknown (m1039) (USFWS, unpub. data). The 3 remaining wolves injured in traps had varying fates: 1 wolf lived more than 2 years after the trapping incident, but its current fate is unknown; 1 was killed by illegal shooting; and another remained alive until at least April 2011 (table 1). Fifty-seven percent of the wolves that were injured during trapping incidents pulled traps loose, including one mortality (m1041) and two with severe injuries (wolf m1039,

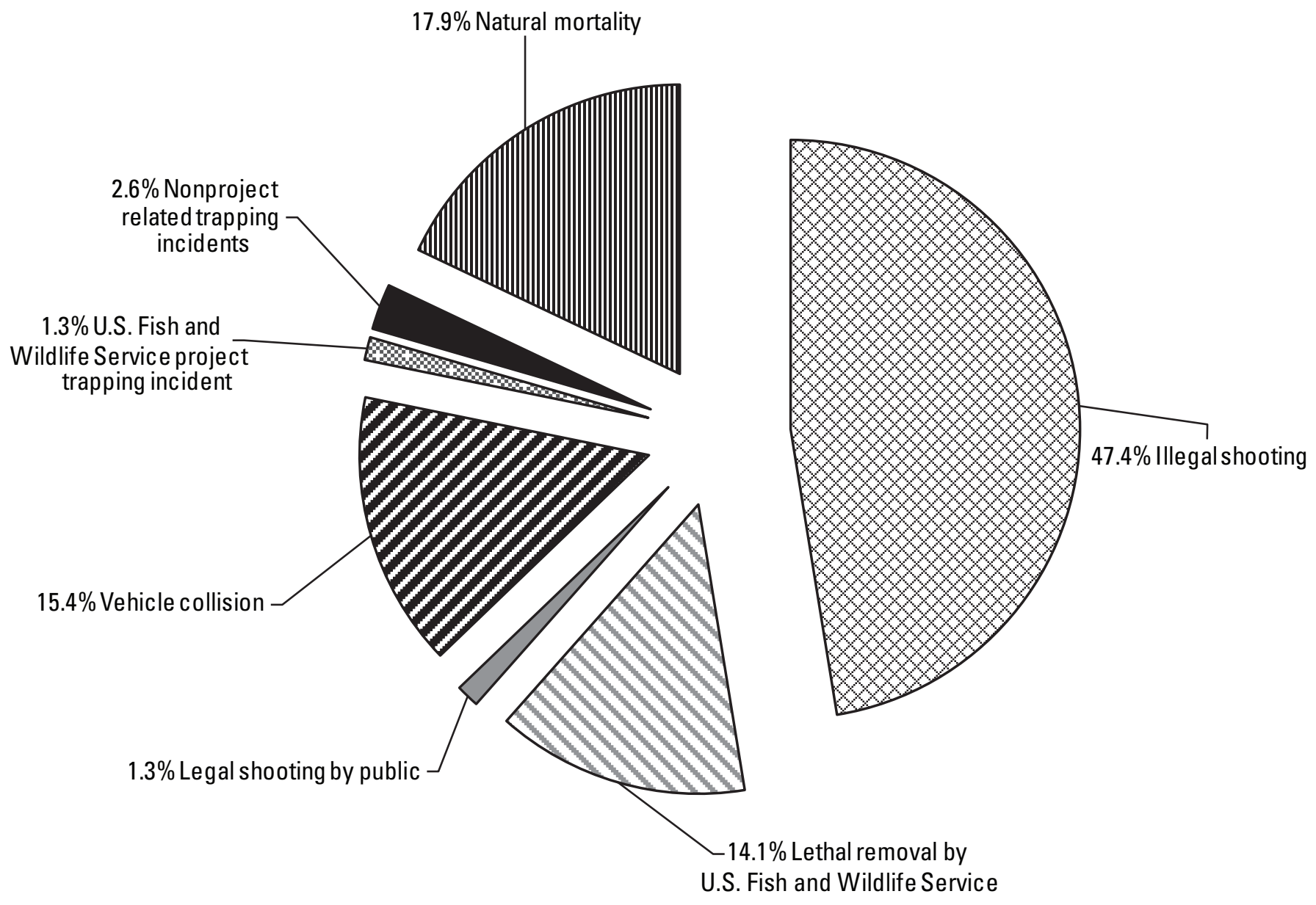

Figure 1. Known sources of mortality for Mexican wolves (Canis lupus baileyi) $(n=78)$ in Arizona and New Mexico, $1998-2010$. 
Table 1. Known nonrecovery program related (that is, private) trapping incidents for Mexican wolves (Canis lupus baileyi) in Arizona and New Mexico, 1998-2010.

[Ariz, Arizona; BRWRA, Blue Range Wolf Recovery Area; IFT, Interagency Field Team; N.M., New Mexico; USFWS, U.S. Fish and Wildlife Service]

\begin{tabular}{|c|c|c|c|c|}
\hline Date & Animal $^{b}$ & Location & Reported injury & Notes/fate ${ }^{c}$ \\
\hline Mar. 18, 2002 & Male 578 & Outside BRWRA - N.M. & None apparent & $\begin{array}{l}\text { Trap set for coyote; wolf removed by trapper; relocated by project } \\
\text { personnel into the BRWRA/lethally removed by USFWS for } \\
\text { livestock depredation in } 2006 \text {. }\end{array}$ \\
\hline Winter 2002-03 & Female562 & BRWRA - N.M. & None apparent & $\begin{array}{l}\text { Wolf released by trapper/Known alive until June 2008; current } \\
\text { fate unknown. }\end{array}$ \\
\hline Winter 2002-03 & Male 583 & BRWRA - N.M. & None apparent & Wolf self released/found dead in May 2008; cause unknown. \\
\hline Nov 20, 2003 & Female858 & Outside BRWRA -Ariz. & None apparent & $\begin{array}{l}\text { Trap set for coyote; wolf relocated by project personnel into the } \\
\text { BRWRA/alive as of March } 2011 \text {. }\end{array}$ \\
\hline Nov. 22, 2003 & Male859 & Outside BRWRA - Ariz. & None apparent & $\begin{array}{l}\text { Trap set for coyote; wolf relocated by project personnel into the } \\
\text { BRWRA/lethally removed by USFWS for livestock } \\
\text { depredation in } 2006 \text {. }\end{array}$ \\
\hline Oct. 15,2005 & Female562 & BRWRA - N.M. & Yes & $\begin{array}{l}\text { IFT observed animal with trap on its foot; captured via } \\
\text { helicopter } 2 \text { days later to remove trap and treat (amputated toes } \\
\text { and remove pad of right foot) the injured foot/suspected alive } \\
\text { until June 2008; current fate unknown }\end{array}$ \\
\hline Mar.26, 2006 & male 1008 & Outside BRWRA - N.M. & None apparent & $\begin{array}{l}\text { Trap set for coyote; wolf removed from trap by project personnel/ } \\
\text { killed by illegal shooting in August } 2008\end{array}$ \\
\hline Oct. 18,2006 & Female923 & BRWRA - N.M. & Yes & $\begin{array}{l}\text { IFT received reports of a wolf with a trap on its foot; F923 was } \\
\text { observed the same day in the same area limping (no trap on } \\
\text { foot)/alive as of April } 2011 .\end{array}$ \\
\hline Winter 2006-07 & male1041 & BRWRA - N.M. & Yes & $\begin{array}{l}\text { Wolf m1041 observed with a trap on its foot in the winter } \\
\text { 2006-2007/died; upon necropsy (at death in May 2007) a } \\
\text { lesion was noted to the right front foot suggestive of a steel trap } \\
\text { type wound. Law enforcement confirms the death was due to } \\
\text { trap-related complications. Trap injury occurred in N.M., and } \\
\text { death occurred in Ariz. }\end{array}$ \\
\hline Jan. 1, 2007 & uncollared & Outside BRWRA - N.M. & Unknown & $\begin{array}{l}\text { Wolf pulled loose with trap. (May be M1107; M1107 first captured } \\
\text { by project personnel in November } 2007 \text { and was missing two } \\
\text { middle toes, consistent with a small trap capture. M1107 is not } \\
\text { included in this compilation because of unknown status of injury } \\
\text { and possible double count with this uncollared wolf). }\end{array}$ \\
\hline Jan. 19, 2008 & Female1112 & BRWRA -N.M. & Yes & $\begin{array}{l}\text { Wolf first captured during helicopter survey and had old (healed) } \\
\text { injury to front foot consistent with a nonproject } \\
\text { trapping incident/killed by illegal shooting in April } 2008 .\end{array}$ \\
\hline Feb. 10, 2008 & male1039 & Outside BRWRA - N.M. & Yes & $\begin{array}{l}\text { Trap set for coyote; wolf pulled loose with trap; captured via } \\
\text { helicopter on Feb. 17, 2008, leg was amputated by project } \\
\text { veterinarian/known alive until January 2009; fate unknown as } \\
\text { of February 2009. }\end{array}$ \\
\hline Nov. 16, 2008 & Male922 & BRWRA - N.M. & Yes & $\begin{array}{l}\text { Found dead;animal died from injuries associated with } \\
\text { nonproject trap. }\end{array}$ \\
\hline Jan. 23, 2009 & Male871 & BRWRA - N.M. & Yes & $\begin{array}{l}\text { Captured during helicopter survey to replace radio collar; a } \\
\text { portion of the front foot was missing, consistent with a } \\
\text { nonproject trapping incident; leg was amputated by project } \\
\text { veterinarian/alive as of April } 2011 \text {. }\end{array}$ \\
\hline Feb. 18, 2009 & Female1106 & BRWRA - N.M. & None apparent & $\begin{array}{l}\text { Wolf removed by trapper; released by project personnel/found } \\
\text { dead in N.M. in November 2010; died of intestinal blockage. }\end{array}$ \\
\hline
\end{tabular}

${ }^{a}$ Data obtained by request from USFWS.

${ }^{\mathrm{b}} \mathrm{Female}=$ adult female, Male $=$ adult male, male $=$ subadult male.

'Information obtained by request from USFWS, from annual reports (USFWS, 2011a), and from monthly project updates. (USFWS, 2011b). 
leg amputated by project veterinarians; wolf F562 toes and pad removed from right foot; table 1). All nonproject trapping incidents in which wolves were uninjured in New Mexico $(n=5)$ and Arizona $(n=2)$ involved traps that remained anchored; animals were released either by the trapper or USFWS personnel or were self-released (table 1). Fates of the five uninjured wolves involved in trapping incidents in New Mexico include survival greater than or equal to 1 year after the trapping incident and current fate unknown $(n=1)$, illegal shooting $(n=1)$, lethal removal by USFWS $(n=1)$, mortality more than 4 years after the trapping incident from unknown cause $(n=1)$ and in the final case, mortality caused by intestinal blockage ( $n=1$, table 1$)$.

For most trapping incidents we were unable to obtain specific information on the type of traps (for example, rubber-padded, offset jaw, laminated and offset), anchoring mechanisms, or species targeted by nonproject trappers whose traps captured Mexican wolves. It seems, however, that all of the trapping incidents involved the use of foothold traps; we could not find any information suggesting that snares were involved in any trapping incident. At least three of the nonproject trapping incidents in New Mexico and two in Arizona involved traps specifically set for coyotes. It is unknown if the traps involved in the other 10 incidents in New Mexico were set for coyotes or regulated furbearers; however, two of the trapping incidents resulting in injuries occurred outside the regulated furbearer trapping season, (that is, November 1-March 31) indicating that these traps were either set for coyote or illegally set out of season.

\section{Trap-injured Wolves and Cattle Depredation}

Four wolves (F562, F923, m1039, M871; table 1) that survived trap-related injuries were involved in depredation incidents resulting in injury or death of 19 head of livestock. Six incidents occurred before individual wolves were injured in traps, and 13 occurred after. There was no significant difference in the frequency of livestock depredation incidents by trap-injured wolves before or after being trapped $\left(\chi_{1}^{2}=2.579, P=0.108\right)$. Most $(n=14)$ of the depredation incidents (4 before trapping and 10 after trapping) were attributed to wolf M871, which had its leg amputated as a result of a trapping incident. After being re-released into the wild, wolf M871 was involved in 10 depredation incidents from August through September 2009; no depredation incidents have been attributed to M871 since the end of September 2009.

\section{Literature Review}

We reviewed 28 sources on trap-injury studies; most were from either the Wildlife Society Bulletin $(n=16)$ or the Journal of Wildlife Management $(n=8)$. Two sources were unpublished progress reports from ongoing research on BMPs for wolf trapping from AFWA, and one was a completed AFWA paper listing BMPs for trapping coyotes in western North America. The last report (Houben and others, 1993) included was from the proceedings of the Great Plains Wildlife Damage Control Workshop, at the University of Nebraska-Lincoln. In addition, we obtained average injury scores and sample sizes for each trap type recommended for use in the BMPs for coyote and bobcat through consultation with the authors (B. White, AFWA, written pers. commun.).

Of the 28 sources, six included information on injuries sustained by gray wolves captured in several types of traps. Nearly half of the articles $(n=13)$ reported testing of various types of traps and snares on coyotes in addition to the data on injury scores obtained from AFWA on traps approved in BMP for coyote. This testing was apparently due to the ready availability and relatively unprotected status of coyotes as well as the existence of government-supported animal damage control efforts, which were used as sources of data in several studies (for example, Hubert and others, 1997; Darrow and others, 2009). Without the inclusion of data on trap-related injuries to coyotes, there would have been little data from which to draw inferences. Other carnivore species involved in trap and snare evaluations included bobcats, lynx ( $L y n x$ canadensis), puma (Puma concolor), red fox (Vulpes vulpes), gray fox (Urocyon cinereoargenteus), arctic fox (Vulpes lagopus), and raccoon (Procyon lotor). Lastly, one article was a summary comparing the results of trapping injury studies conducted on several species, most of which were also included in this report (Andelt and others, 1999).

The 24 sources describing original field research on trap-related trauma used a variety of indices for evaluating the severity of injuries. The ISO procedures intended to standardize severity scores for capture-induced trauma did not exist until 1999 (Darrow and others, 2009), and three basic systems, and modifications thereof, were used in most of the studies. Olsen and others (1986) developed a scale that was used in four studies, all conducted on coyotes (table 2). A system devised by Van Ballenberghe (1984), and used in three studies involving wolves, assigned trapped animals to one of four severity categories (table 3 ). Lastly, six sources and the BMP studies (AFWA, 2006a) incorporated a system based on the 1999 ISO standards; these studies involved wolves, coyotes, bobcat, and red fox (table 4 and references therein). The ISO-based system is described in detail by Darrow and others (2009). Eleven of these 24 sources either did not use these systems or did not represent their data completely enough to be used in quantitative comparison.

\section{Foothold Traps}

The most frequently tested type of trap was the smoothjaw, nonlaminated steel foothold trap. Studies which evaluated other devices either included these common steel traps for comparison or incorporated results of other reports which did. These devices are probably the most popular among North American trappers, particularly for capturing wolf-like canids 
Table 2. Mean injury score ${ }^{a}$ for coyotes (Canis latrans) from studies ${ }^{b}$ evaluating capture injuries resulting from the use of foothold traps and nonlethal cable snares.

\begin{tabular}{|c|c|c|c|c|c|c|c|c|c|}
\hline \multicolumn{2}{|c|}{ Conventional steel-jaw ${ }^{1,2,3}$} & \multicolumn{2}{|c|}{ Laminated and offset $^{1}$} & \multicolumn{2}{|c|}{ Rubber-padded $d^{2,3,4}$} & \multicolumn{2}{|c|}{ Cable foot snare ${ }^{3,4}$} & \multicolumn{2}{|c|}{ Nonlethal neck snare ${ }^{4}$} \\
\hline Mean & $n$ & Mean & $n$ & Mean & $n$ & Mean & $n$ & Mean & $n$ \\
\hline 80.9 & 74 & 63 & 29 & 31.0 & 114 & 35.0 & 27 & 0.8 & 13 \\
\hline
\end{tabular}

${ }^{a}$ Numerical leg injury scores are additive for each trapped individual, but injuries which were part of higher-scoring injuries (that is, tendon damage which was associated with a joint luxation, or cutaneous laceration caused by a compound fracture) were not double-counted. Point values are defined by Olsen and others (1986) below. Severity of the injury increases with the severity index; that is, a larger index denotes a more severe injury. "Apparently normal=0, Edematous swelling and hemorrhage $=5$, Cutaneous laceration $<2 \mathrm{~cm}=5$, Cutaneous laceration $>2 \mathrm{~cm}=10$, Tendon and ligament laceration=20, Joint subluxation $=30$, Joint luxation $=50$, Compression fraction above or below carpus or tarsus $=30$, Simple fracture at or below carpus or tarsus $=50$, Compound fracture at or below carpus or tarsus $=75$, Simple fracture above carpus or tarsus $=100$, Compound fracture above carpus or tarsus $=200$, Amputation $=400 "$

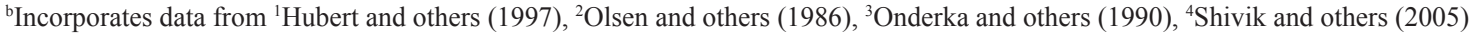

Table 3. Percentage of wolf (Canis lupus) injuries by severity class summarized from studies ${ }^{\text {a }}$ evaluating wolf injuries caused by various types of foothold traps. In general, the severity of the injury increases with the severity score.

\begin{tabular}{|c|c|c|c|c|c|c|}
\hline $\begin{array}{l}\text { Injury severity } \\
\text { class }^{\text {b }}\end{array}$ & $\begin{array}{l}\text { Conventional } \\
\text { smooth-jaw }\end{array}$ & Offset smooth-jaw ${ }^{1}$ & Toothed, offset ${ }^{1}$ & Toothed, no offset ${ }^{1}$ & Rubber-padded ${ }^{2}$ & $\begin{array}{c}\text { All unpadded } \\
\operatorname{traps}^{c, 2,3}\end{array}$ \\
\hline Class I & 17 & 18 & 3 & 10 & 72 & 15 \\
\hline Class III & 27 & 30 & & 16 & 8 & 25 \\
\hline Class IV & 7 & 5 & & 12 & 1 & 8 \\
\hline
\end{tabular}

${ }^{\mathrm{a}}$ Incorporates data from ${ }^{1} \mathrm{Kuehn}$ and others (1986), ${ }^{2}$ Frame and Meier (2007), ${ }^{3}$ Van Ballenberghe (1984).

${ }^{b}$ Each captured animal was assigned to one of four injury categories as described by Van Ballenberghe (1984): Class I= "slight foot and/or leg edema with no lacerations and no evidence of broken bones or dislocated joints," Class II= "moderate edema with a skin laceration $2.5 \mathrm{~cm}$ or less long, bones and joints as in class I," Class III= "injuries-skin laceration greater than $2.5 \mathrm{~cm}$ long with visible damage to underlying tissues, tendons intact, bone breakage limited to one phalanx or metacarpal," Class IV= "various combinations of deep, wide lacerations, severed tendons, broken metacarpals, broken radius and ulna bones, and joint dislocations of the leg."

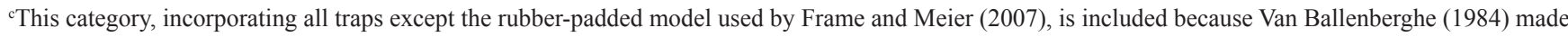
109 captures of wolves using three models of smooth-jawed and toothed offset steel traps but did not have sufficiently large sample sizes with all devices to make a comparison, so no differentiation was made among these models. A foot snare was also tested, but sample size was insufficient for inclusion in the original work.

Table 4. Mean injury score ${ }^{a}$ for red fox (Vulpes vulpes), coyotes (Canis latrans), and wolves (Canis lupus) from studies ${ }^{b}$ evaluating capture injuries resulting from the use of foothold traps and nonlethal cable snares.

\begin{tabular}{|c|c|c|c|c|c|c|c|c|c|c|c|c|c|c|}
\hline Species & $\begin{array}{l}\text { Foot } \\
\text { snare }\end{array}$ & $n$ & $\begin{array}{l}\text { Neck } \\
\text { snare }\end{array}$ & $n$ & $\begin{array}{c}\text { Laminated, } \\
\text { offset with stake }\end{array}$ & $n$ & $\begin{array}{c}\text { Laminated, } \\
\text { offset with drag }\end{array}$ & $n$ & $\begin{array}{c}\text { Offset } \\
\text { with drag }\end{array}$ & $n$ & $\begin{array}{c}\text { Offset } \\
\text { with stake }\end{array}$ & $n$ & $\begin{array}{c}\text { Padded } \\
\text { with stake }\end{array}$ & $n$ \\
\hline Red fox & 21.7 & $27^{1}$ & 13.4 & $22^{1}$ & & & & & & & & & & \\
\hline Gray wolf & & & & & 23.0 & $5^{5}$ & 51.0 & $10^{6}$ & 53.4 & $35^{6}$ & 47.1 & $24^{6}$ & & \\
\hline
\end{tabular}

aInjury scores were assigned on the basis of the 1999 International Organization for Standardization (ISO) procedures. Scores are cumulative. Note that in the case of Phillips and others (1996), ISO procedures had not yet been published; however, the system used in that report is sufficiently comparable to include herein. The scores associated with each category of injury are described below, as in Darrow and others (2009): 5= "Edematous swelling, hemorrhage,or cutaneous abrasion," $10=$ "Cutaneous laceration, minor periosteal abrasion or minor (below carpus or tarsus) subcutaneous soft-tissue maceration erosion," $25=$ "Severance of minor tendon or ligament," 30= "Major (above carpus or tarsus) subcutaneous soft-tissue maceration erosion, major periosteal abrasion, or permanent tooth fracture exposing pulp cavity," $50=$ "Simple fracture at or below the carpus or tarsus," $100=$ "Severance of major tendon or ligament or death."

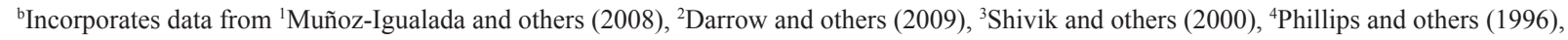
${ }^{5}$ White (2010), ${ }^{6}$ White (2009). 
(Olsen and others, 1986; Phillips and others, 1996; Andelt and others, 1999). These traps consistently resulted in more severe injuries to wolves (Van Ballenberghe, 1984; Kuehn and others, 1986; Sahr and Knowlton, 2000; Frame and Meier, 2007), coyotes (Onderka and others, 1990; Phillips and others, 1996; Hubert and others, 1997; AFWA, unpub. data), and other carnivores (Olsen and others, 1988; Kreeger and others, 1990; Earle and others, 2003) (tables 2, 3, and 4). Injuries that were more commonly sustained by animals captured in these traps were fractures, major cutaneous lacerations, joint luxation, tendon damage (Kuehn and others, 1986; Kreeger and others, 1990; Andelt and others, 1999; Sahr and Knowlton, 2000), and possibly limb freezing that was due to the restriction of circulation caused by the pinching of the limb (Onderka and others, 1990). Some of the BMP-approved, steel-jaw traps tested on bobcats, however, caused less severe injuries and were comparable to other trap types (AFWA, unpub. data).

Steel foothold traps with varying degree of offset did not typically result in lower injury scores than nonoffset, smoothjaw traps (tables 2, 3, and 4), except one model also featuring laminated jaws (Houben and others, 1993), which resulted in less severe injuries to coyotes and in BMP-approved offset traps tested on bobcats and coyote (AFWA, unpub. data).

Steel, laminated traps were tested only on coyotes (table 2 and 4) and in the BMPs for coyote and bobcat (AFWA, 2006a,b,c). In the three published studies, these traps resulted in somewhat lower injury scores than did the standard and offset steel-jaw traps, but injury scores were still higher relative to other devices. In one evaluation (Houben and others, 1993) a trap modified by both laminating and offsetting the jaws resulted in lower injury scores for coyote than other more conventional foothold models. Steel, laminated traps without an offset were not recommended for use by AFWA in their BMP for coyote, but one such trap did meet BMP criteria for bobcat (AFWA 2006a,b,c; AFWA, unpub. data).

Traps with offset, toothed jaws were tested on wolves in two studies (Van Ballenberghe, 1984; Kuehn and others, 1986); these resulted in markedly reduced injuries compared to smooth-jawed traps, with no "moderate" or "severe" injuries reported for this trap type in one study (Kuehn and others, 1986) (table 3). These results were similar to those for rubber-jawed traps.

Among the rigid-jawed, foothold traps evaluated, rubber-padded traps consistently proved to be the most effective at mitigating injuries to all species of carnivores (tables 2, 3, and 4). Many ( $n=12)$ of the studies tested rubberpadded traps against other devices. Of these, 8 were tested on coyotes, 1 on gray wolves, 2 on bobcats, 2 on red foxes, 1 on gray foxes, 1 on raccoons, and 1 on lynx (tables 2, 3, and 4). In nearly all studies, there was a lower frequency of severe injury to captured animals compared with unpadded foothold traps; the single exception was the consistently minor injuries caused by the toothed trap tested by Kuehn and others (1986). Data from BMP were consistent with other studies for coyote, with rubber-padded traps having lower severity scores than other types of jaw traps (AFWA, unpub. data). One exception was the BMP study conducted on bobcat in which mean severity scores for rubber-padded traps overlapped with other trap types, particularly laminated and offset traps (AFWA, unpub. data).

\section{Snares}

Several models of cable foot snares, as well as lethal and nonlethal cable neck snares were evaluated, primarily on coyotes. Foot snares were tested in nine published studies and in the BMP studies on bobcat and coyote. Six of these involved coyotes; the other five were conducted on puma, lynx, bobcat, red foxes, and wolves. There was considerable variation in the severity of injuries sustained from the use of different foot snare models when they were tested on coyotes. Onderka and others (1990) tested two types of foot snares, one of which produced injuries similar to that of an unpadded foothold trap, with the other model causing injuries similar to a padded foothold trap. Other authors found that various snares resulted in severity scores ranging from somewhat lower to slightly higher than those attributed to rubberpadded foothold traps (Shivik and others, 2000; Darrow and others, 2009). Studies evaluating foot snares with other species resulted in varying severity scores. Wolves (Van Ballenberghe, 1984), red foxes (Muñoz-Igualada and others, 2008), and pumas (Logan and others, 1999) generally had low to extremely low frequencies of severe injury (tables 2 and 4). Severity scores from BMP studies on coyote and bobcat were lower than or comparable to severity scores from rubber-padded traps (AFWA, unpub. data). Lynx, however, frequently sustained serious injuries including radius and ulna fractures when caught in a foot snare (Mowat and others, 1994). The authors noted, however, that the cable restraint never resulted in limb freezing as did the padded foothold trap tested, and that such snares might still be a better option during extremely cold weather, especially if the snare is securely anchored (improperly anchored snares were thought to be the cause of many of the severe injuries sustained by lynx) (tables 2 and 4).

Four studies were conducted by using nonlethal cable neck snares: two on coyotes and two on red fox (table 4). Low to extremely low frequencies of serious injuries were recorded by using these devices (Shivik and others, 2000; Shivik and others, 2005; Muñoz-Igualada and others, 2008; Muñoz-Igualada and others, 2010). Three models of lethal neck snare, each with a breakaway device intended to release deer (mule deer [Odocoileus hemionus] and white-tailed deer [Odocoileus virginianus]) and livestock, were tested on coyotes (Phillips, 1996). Although these devices proved to be highly efficient (that is, near 90 percent of possible captures) at catching and quickly killing coyotes, they did not consistently release deer. Fifty-one of 91 deer were unable to break free; 47 died in the snares (Phillips, 1996). 


\section{Discussion}

The potential impacts of regulated furbearer trapping on reintroduced Mexican wolves in New Mexico has become a concern of some sectors of the public and, in part, prompted now former Governor Bill Richardson to issue Executive Order 2010-029, temporarily banning regulated furbearer trapping on the BRWRA. Among the reasons cited in the order in support of the ban were the 1976 listing of the subspecies under the Endangered Species Act, the small size of the reintroduced population (reintroduced as $10 \mathrm{j}$ non-essential experimental population), and injuries sustained by Mexican wolves because of trapping activities. It was also noted in the order that such injuries could potentially increase predation on livestock because of the inability of injured wolves to effectively hunt native prey.

The current population, estimated at 50 wolves (USFWS, unpub. data) is still well short of the original U.S. Fish and Wildlife Service's 2005 recovery goal of 100 free-ranging individuals. To date, 78 wolf mortalities have been documented and an additional 23 animals have been permanently removed from the wild by USFWS. Approximately 82 percent of the documented mortalities were caused by humans with only 2.6 percent of all mortalities being caused by nonproject trappers (fig. 1).

We were unable to obtain specific information on the type of traps or anchoring mechanisms involved in most of the documented trapping incidents of Mexican wolves. However, the majority of injuries, including the most severe ones, occurred during trapping incidents in which the traps were pulled loose, indicating that the method of anchoring was insufficient to hold a wolf until it could be released by a trapper or USFWS personnel. Conversely, most of the uninjured wolves were caught in traps in which the anchoring mechanism remained secure. General recommendations by AFWA for trappers suggest that the anchoring system should be sufficient to "hold the largest furbearer that might be captured" (AFWA, 2006a). Anchoring systems sufficient to hold coyotes or regulated furbearers may not be strong enough to hold Mexican wolves, potentially leading to more severe injuries to wolves if the trap is pulled loose.

The species targeted by trappers whose traps were involved in these incidents were not available for most cases; however, five trapping incidents (three in New Mexico and two in Arizona) involved traps that were set for coyotes. In addition, two of the trapping incidents in New Mexico occurred outside the regulated furbearer trapping season, indicating that these two traps were either set for coyote or illegally set out of season. As noted previously, residents trapping specifically to protect domestic animals, or trapping of coyotes were not affected by the trapping ban instituted by the Governor's executive order; therefore, the incidents involving traps set for coyotes would not have been prevented by the trapping ban in the BRWRA.

We found little evidence that trap-related injuries resulted in increased cattle depredation. Our results may have been influenced either by the low number of injured wolves that were included in our analysis or the fact that most depredation incidents involved a single wolf. There are little data from other studies to support the contention that injured wolves are more likely to depredate livestock (Fritts and others, 1992; Fritts and others, 2003).

There were some definite differences in the level of risk presented to Mexican wolves by trapping devices legal for use in New Mexico. Unpadded, smooth-jawed steel traps, even if laminated or offset, generally presented the highest potential for injury to all species targeted in the studies. Wolves were no exception, with high percentages of those caught in these traps sustaining injuries including fractures, major cutaneous lacerations, and tendon damage (Sahr and Knowlton, 2000; Frame and Meier, 2007); however, the study by Houben and others (1993) suggested that traps that were both laminated and offset resulted in less severe injuries than smooth-jawed steel traps, laminated steel traps, or offset steel traps.

One trap that nearly eliminated serious injury to wolves, albeit in only one study, was a toothed, offset foothold model (Kuehn and others, 1986). Additionally, no studies were found that evaluated the potential for harm to other species caused by toothed-jaw traps. Toothed traps are prohibited under current (2011-2012) New Mexico trapping regulations (NMDGF 2011), and because these traps are illegal for recreational trapping in many other jurisdictions, few models are commercially available. A few companies nevertheless offer such traps in sizes specifically intended for use on large carnivores, including wolves.

Rubber-padded foothold traps generally resulted in less severe injury to all species captured than other types of foothold traps (Olsen and others, 1988; Andelt and others, 1999; Frame and Meier, 2007). The authors of most of these studies were satisfied with the performance of these traps and recommended them as a sound option for both trappers and researchers, except possibly during extremely cold conditions when a cable foot snare may be safer because there is reduced potential for freezing limbs (Mowat and others, 1994). BMP data for bobcat, however, indicated that some models of padded-jaw traps resulted in severity scores that were comparable to traps that were offset and laminated or were offset with wide cast jaws; padded-jaw traps recommended in BMPs for coyote resulted in lower severity scores than all other jaw traps (AFWA, unpub. data). Based on the results of these studies and the focus of assessing trap-related injury to wolves, it is clear that rubber-padded foothold traps generally produced the lowest severity scores for wolf-like canids.

Because of well-founded concerns about the capture efficiency and even the injury mitigation capabilities of early rubber-padded traps, distrust of these traps still exists among trappers (Linscombe and Wright, 1988; Linhart and Dasch, 1992). Currently manufactured models have gone through several modifications as a result of trapper dissatisfaction, and more recent studies have shown them to be as effective as unpadded models at catching and holding furbearers (Phillips and Mullis, 1996; Earle and others, 2003). Several 
models of padded-jaw traps are among those recommended by AFWA for trapping of coyote and bobcat (AFWA, 2003; AFWA, 2006a,b,c).

The various cable foot snares evaluated, although somewhat inconsistent in performance, generally resulted in lower severity scores than did unpadded, non-toothed foothold traps. Devices in some studies equaled or exceeded the performance of rubber-padded traps in terms of trauma mitigation (Logan and others, 1999; Shivik and others, 2005; Muñoz-Igualada and others, 2005; Muñoz-Igualada and others, 2008; AFWA, unpub. data). Other studies, however, indicated that certain foothold snares could result in injuries comparable to unpadded steel traps if the snares were not properly anchored (Onderka and others, 1990; Mowat and others, 1994).

The nonlethal cable neck snares used in four studies were found to be fairly safe devices for capturing red foxes and coyotes with a low potential for harm to nontarget species (Shivik and others, 2000; Shivik and others, 2005; Muñoz-Igualada and others, 2008; Muñoz-Igualada and others, 2010). No animals were permanently harmed by these devices, with the exceptions of one coyote killed by a malfunctioning device and a small percentage of canids that damaged teeth on the cable. These snares may be a viable option for use in areas where there is potential for wolf capture; however, we did not find any studies that specifically used nonlethal cable neck snares on wolves.

The single study that examined lethal neck snares equipped with breakaway devices intended to release nontarget species larger than coyotes resulted in deaths of 47 out of 91 deer (mule deer and white-tailed deer) because they were unable to generate enough force to escape (Phillips, 1996). Mexican wolves, especially pups, overlap in size with coyotes and are generally smaller than the deer killed in these snares.

Although some of the articles did describe in detail the trap size, chains, swivels, stakes, and drags employed, notably lacking were comparisons of these modifications and how they influenced the severity of injuries; some of the variability in severity scores documented could be due to differences in trap modifications other than jaw type. Two studies (White, 2009; White, 2010) did test identical traps on wolves with either stakes or drags for anchoring (table 4), but no difference was found between anchoring systems; field research for this project is ongoing. Further evaluation of factors other than jaw type for minimizing trap-related injuries may be warranted.

Certain types of traps and snares clearly stood out as being more likely to reduce injury to both target and nontarget terrestrial mammals, including large canids. With the exception of some padded-jaw traps tested in BMP for bobcat, rubber-padded models consistently resulted in greatly reduced trauma scores for all species for which they were evaluated. Toothed, offset steel-jawed traps (currently legally restricted), resulted in severity scores classified as light-tomoderate for wolves and were comparable to rubber-padded foothold traps. Almost without exception, smooth-jawed steel traps, even if offset or laminated, were associated with more severe injuries than other devices used to capture wolves and other carnivores. Smooth-jawed steel traps that were both laminated and offset, however, resulted in fewer injuries and lower severity scores than unmodified smooth-jawed traps, offset smooth-jawed traps, or laminated traps, although injury scores were not reduced to the extent that they were with most rubber-padded traps.

Of the varied human impacts, trapping-related injury and mortality to Mexican wolves is relatively minimal. Nevertheless, modifications to traps can be implemented to reduce impacts even further. Human-induced mortality has most likely impeded the recovery of the Mexican wolf, and those parties concerned with reestablishing the species could take a close look at those human-caused impacts of greatest conservation concern.

\section{References Cited}

Andelt, W.F., Phillips, R.L, Schmidt, R.H., and Gill, R.B., 1999, Trapping furbearers: an overview of the biological and social issues surrounding a public policy controversy: Wildlife Society Bulletin, v. 27, p. 53-64.

Association of Fish and Wildlife Agencies (AFWA), 2003, Best management practices for trapping coyotes in the Eastern United States: Washington, D.C., Association of Fish and Wildlife Agencies, 13 p.

Association of Fish and Wildlife Agencies (AFWA), 2006a, Best management practices for trapping in the United States: introduction: Washington, D.C., Association of Fish and Wildlife Agencies, $13 \mathrm{p}$.

Association of Fish and Wildlife Agencies (AFWA), 2006b, Best management practices for trapping coyotes in the Western United States: Washington, D.C., Association of Fish and Wildlife Agencies, 12 p.

Association of Fish and Wildlife Agencies (AFWA), 2006c, Best management practices for trapping bobcats in the United States: Washington, D.C., Association of Fish and Wildlife Agencies, 14 p.

Darrow, P.A., Skirpstunas, R.T., Carlson, S.W., and Shivik, J.A., 2009, Comparison of injuries to coyote from 3 types of cable foot-restraints: Journal of Wildlife Management, v. 73 , p. 1441-1444.

Earle, R.D., Lunning, D.M., Tuovila, V.R., and Shivik, J.A., 2003, Evaluating injury mitigation and performance of \#3 Victor Soft Catch (R) traps to restrain bobcats: Wildlife Society Bulletin, v. 31, p. 617-629.

Frame, P.F., and Meier, T.J., 2007, Field-assessed injury to wolves captured in rubber-padded traps: Journal of Wildlife Management, v. 71, p. 2074-2076. 
Fritts, S.H., Paul, W.J., Mech, L.D., and Scott, D.P., 1992, Trends and management of wolf-livestock conflicts in Minnesota: U.S. Fish and Wildlife Service Resource Publication 181, $27 \mathrm{p}$.

Fritts, S.H., Stephenson, R.O., Hayes, R.D., and Boitani, Luigi., 2003, Wolves and humans, in Mech, D.L., and Boitani, Luigi., eds., Wolves: behavior, ecology and conservation: Chicago, Ill., University of Chicago Press, p. 289-316.

Houben, J.M., Holland, Merrilee., Jack, S.W., and Boyle, C.R., 1993, An evaluation of laminated offset jawed traps for reducing injuries to coyotes: Great Plains Wildlife Damage Control Workshop Proceedings, 147-153.

Hubert, G. F., Hungerford, L.L., and Bluett, R.D., 1997, Injuries to coyotes captured in modified foothold traps: Wildlife Society Bulletin, v. 25, p. 858-863.

International Organization for Standardization (ISO), 1999, Animal (mammal) traps, part 5, Methods for testing restraining traps: Geneva, Switzerland, International Organization for Standardization, International Standard ISO/DIS 10990-5.

International Association of Fish and Wildlife Agencies (IAFWA), 1997, Improving animal welfare in U.S. trapping programs: process recommendations and summaries of existing data: Washington, D.C., International Association of Fish and Wildlife Agencies (currently Association of Fish and Wildlife Agencies).

Iossa, Graziella., Soulsbury, C.D., and Harris, Stephen., 2007, Mammal trapping: a review of animal welfare standards of killing and restraining traps: Animal Welfare, v.16, p. 335-352.

Kreeger, T.J., White, P.J., Seal, U.S., and Tester, J.R., 1990, Pathological responses of red foxes to foothold traps: Journal of Wildlife Management, v. 54, p. 147-160.

Kuehn, D.W., Fuller, T.K., Mech, L.D., Paul, W.J., Fritts, S.H., and Berg, W.E., 1986, Trap-related injuries to gray wolves in Minnesota: Journal of Wildlife Management, v. 50, p. 90-91.

Linhart, S.B., and Dasch, G.J., 1992, Improved performance of padded jaw traps for capturing coyotes: Wildlife Society Bulletin , v. 20, p. 63-66.

Linscombe, R.G., and Wright, V.L., 1988, Efficiency of padded foothold traps for capturing terrestrial furbearers: Wildlife Society Bulletin, v. 16, p. 307-309.

Logan, K.A., Sweanor, L.L., Smith, J.F., and Hornocker, M.G., 1999, Capturing pumas with foot-hold snares: Wildlife Society Bulletin, v. 27, p. 201-208.
Mowat, Garth., Slough, B.G., and Rivard, René., 1994, A comparison of three live capturing devices for lynx: capture efficiency and injuries: Wildlife Society Bulletin, v. 22 , p. 644-650.

Muñoz-Igualada, Jaime., Shivik, J.A., Dominguez, F.G., Gonzalez, L.M., Moreno, A.A., Olalla, M.F., and Garcia, C.A., 2010, Traditional and new cable restraint systems to capture fox in central Spain: Journal of Wildlife Management, v. 74, p. 181-187.

Muñoz-Igualada, Jaime., Shivik, J.A., Dominguez, F.G., Lara, José., and Gonzalez, L.M., 2008, Evaluation of cage-traps and cable restraint devices to capture red foxes in Spain: Journal of Wildlife Management, v. 72, p. 830-836.

Muth, R.M., Zwick, R.R., Mather, M.E., Organ, J.F., Daigle, J.J., and Jonker, S.A., 2006, Unnecessary source of pain and suffering or necessary management tool: attitudes of conservation professionals toward outlawing leghold traps: Wildlife Society Bulletin, v. 34, p. 706-715.

New Mexico Department of Game and Fish (NMDGF), 2011, Big game and trapper rules and information: Santa Fe, N.M., New Mexico Department of Game and Fish, 63 p.

Olsen, G.H., Linhart, S.B., Holmes, R.A., Dasch, G.J., and Male, C.B., 1986, Injuries to coyotes caught in padded and unpadded steel foothold traps: Wildlife Society Bulletin, v. 14, p. $219-223$.

Olsen, G.H., Linscombe, R.G., Wright, V.L., and Holmes, R.A., 1988, Reducing injuries to terrestrial furbearers by using padded foothold traps: Wildlife Society Bulletin, v. 16, p.303-307.

Onderka, D.K., Skinner, D.L., and Todd, A.W., 1990, Injuries to coyotes and other species caused by 4 models of footholding devices: Wildlife Society Bulletin, v. 18, p. 175-182.

Phillips, R.L., 1996, Evaluation of 3 types of snares for capturing coyotes: Wildlife Society Bulletin, v. 24, p. 107-110.

Phillips, R.L., Gruver, K.S., and Williams, E.S., 1996, Leg injuries to coyotes captured in three types of foothold traps: Wildlife Society Bulletin, v. 24, p. 260-263.

Phillips, R.L., and Mullis, Curt., 1996, Expanded field testing of the No 3 Victor Soft Catch(R) trap: Wildlife Society Bulletin, v. 24, p.128-131.

Proulx, Gilbert, Pawlina, I.M., Onderka, D.K., Badry, M.J., Seidel, Ken, 1994, Field evaluation of the number 1 1/2 steel-jawed leghold and the Sauvageau 2001-8 traps to humanely capture arctic fox: Wildlife Society Bulletin, v. 22, p. 179-183. 
Sahr, D.P., and Knowlton, F.F., 2000, Evaluation of tranquilizer trap devices (TTDs) for foothold traps used to capture gray wolves: Wildlife Society Bulletin, v. 28 , p. 597-605.

Shivik, J.A., Gruver, K.S., and DiLiberto, T.J., 2000, Preliminary evaluation of new cable restraints to capture coyotes: Wildlife Society Bulletin, v. 28, p. 606-613.

Shivik, J.A., Martin, D.J., Pipas, M.J., Turnan, John, and DiLiberto, T.J., 2005, Initial comparison: jaws, cables, and cage-traps to capture coyotes: Wildlife Society Bulletin, v. 33 , p. $1375-1383$.

U.S. Fish and Wildlife Service (USFWS), 2010, Mexican wolf population statistics: Accessed March 12, 2011 at http:// www.fws.gov/southwest/es/mexicanwolf/MWPS.shtml.

U.S. Fish and Wildlife Service (USFWS), 2011a, Annual reports on the Mexican Wolf Recovery Program: accessed April 14, 2011 at http://www.fws.gov/southwest/es/ mexicanwolf/documents.shtml.

U.S. Fish and Wildlife Service (USFWS), 2011b, Blue Range Wolf Reintroduction Area (BRWRA) monthly project updates: accessed April 14, 2011 at http://www.fws.gov/ southwest/es/mexicanwolf/BRWRP_notes.cfm.

Van Ballenberghe, Victor, 1984, Injuries to wolves sustained during live-capture: Journal of Wildlife Management, v. 48, p. $1425-1429$.

White, Bryant, 2009, Testing restraining traps for the development of best management practices for trapping gray wolf in the United States: Washington, D.C., Association of Fish and Wildlife Agencies, 9 p.

White, Bryant, 2010, Testing restraining traps for the development of best management practices for trapping gray wolf in the United States: Washington, D.C., Association of Fish and Wildlife Agencies, $10 \mathrm{p}$. 


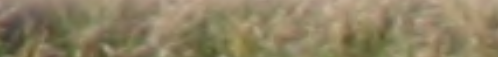

$4 \%$

The tet W.

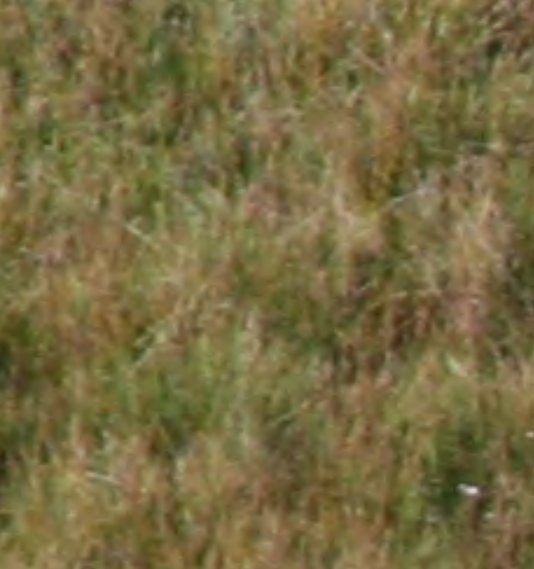

x.

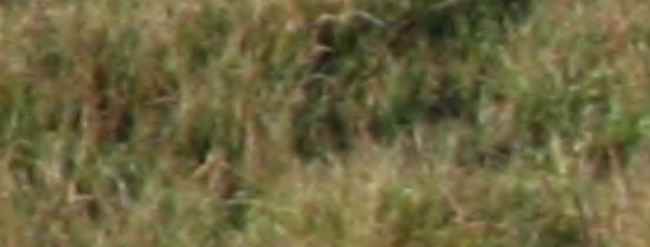
1. 291015 